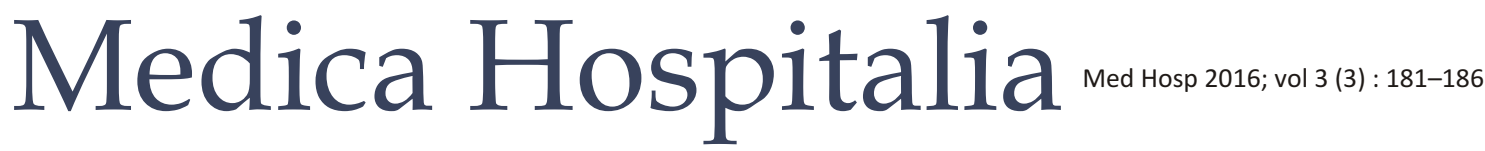

Original Article

\section{Hubungan Rentang Tangan dan Fungsi Paru Pada Anak Asma}

\author{
Hanif Kusumoํㅜ, Maria Mexitalia², MS Anam² \\ ${ }^{1}$ Mahasiswa Program Pendidikan S-1 Pendidikan Dokter Fakultas Kedokteran Universitas Diponegoro \\ ${ }^{2}$ Departemen Ilmu Kesehatan Anak Fakultas Kedokteran Universitas Diponegoro/RSUP Dr. Kariadi Semarang
}

\begin{abstract}
Abstrak
Latar belakang : Asma merupakan penyakit yang sering ditemukan pada anak usia sekolah. Diperlukan tes fungsi paru (TFP) dalam diagnosis asma. Nilai tes fungsi paru dapat diprediksi dari tinggi badan. Ada kalanya deformitas atau kelainan tertentu pada anak menyebabkan anak tidak dapat diukur tinggi badannya. Rentang tangan merupakan parameter tubuh terbaik yang dapat menggantikan tinggi badan dalam memprediksi nilai fungsi paru. Penelitian ini bertujuan untuk mengetahui hubungan antara rentang tangan dan fungsi paru pada anak usia sekolah dengan riwayat asma di Semarang.

Metode : Rancangan penelitian adalah cross-sectional pada Maret-Juni 2015. Subjek penelitian adalah anak dengan riwayat asma usia 6 sampai 12 tahun yang dievaluasi menggunakan kuesioner ISAAC. Data antropometrik dan nilai tes fungsi paru didapatkan dengan mengukur subjek secara langsung. Uji statistik yang digunakan adalah uji Pearson dan uji Spearman serta dilakukan juga uji regresi linier.

Hasil : Subjek penelitian berjumlah 30 anak usia 6 sampai 12 tahun. FEV1 dan PEFR menunjukkan korelasi yang signifikan dengan rentang tangan. Hasil uji regresi linier menunjukkan beberapa persamaan regresi untuk menentukan nilai tes fungsi paru dari indeks antropometrik pada anak asma usia 6 sampai 12 tahun antara lain $\mathrm{FVC}=0,025 * \mathrm{RT}-1.676, \mathrm{FEV} 1=0,23 * \mathrm{RT}-1,482$, dan PEFR=0,043*RT-2,592.

Simpulan : FVC, FEV1, dan PEFR menunjukkan korelasi positif yang signifikan dengan rentang tangan pada anak asma. Persamaan regresi nilai prediksi fungsi paru dari rentang tangan belum bisa dikatakan akurat untuk diaplikasikan pada anak-anak di Indonesia dengan riwayat asma dikarenakan jumlah sampel yang sedikit.
\end{abstract}

Kata kunci : Asma, rentang tangan, anak usia sekolah, tes fungsi paru

\section{The relationship of arm span and pulmonary function in asthmatic children}

\begin{abstract}
Background : Asthma is a disease that was often found in schoolaged children. Pulmonary function tests (PFT) used in the diagnosis and treatment of asthma. Height has been used to predict pulmonary function test values. Height of the children sometimes couldn't be measured due to skeletal abnormality. Arm span was known to be an alternative of height in predicting lung function. The aims of this study was to determine the relationship between arm span and lung function in school-age children with a history of asthma in Semarang.

Methods : This was a cross-sectional study conducted in March-June 2015. The subjects were evaluated using the ISAAC questionnaire and measured directly to obtain the data. The statistical test used was Pearson test and Spearman's test and also linear regression test.

Results : The research subjects were 30 children with a history of asthma aged 6 to 12 years. FEV1 and PEFR have shown a significant correlation with arm span. Regression analysis resulted regression equations to determine pulmonary function test values from arm span in asthmatic children aged 6 to 12 years such as $\mathrm{FVC}=0.025^{*}$ ArmSpan-1676, FEV1 = 0:23 * ArmSpan-1482, and PEFR $=0.043$ * ArmSpan-2592.

Conclusion : FVC, FEV1 and PEFR showed significant positive correlation with arm span in children with asthma. The regression equation predictive value in lung function from arm span was not accurate enough to be applied for all children in Indonesia with a history of asthma due to small sample size.
\end{abstract}

Keywords : Asthma, arm span, school-age children, pulmonary function tests 


\section{PENDAHULUAN}

Asma merupakan penyakit paru kronis yang sering ditemukan pada anak usia sekolah. Dengan kata lain, penyakit asma sering menyebabkan anak bolos sekolah dan sering merupakan indikasi untuk masuk perawatan rumah sakit. Penyakit asma pada anak diperlukan pertimbangan terhadap kehidupan sehari-harinya. Anak yang menderita asma mengalami gangguan aliran udara pada saluran pernapasan kecil. ${ }^{1}$

Prevalensi asma di Indonesia menurut Riset Kesehatan Dasar tahun 2013 oleh Kementrian Kesehatan Republik Indonesia secara keseluruhan adalah 4,5 persen namun belum diketahui secara pasti prevalensi di tiap wilayah Indonesia. Penyakit asma lebih sering ditemukan di kalangan usia muda dibandingkan usia tua. ${ }^{2}$ Hasil penelitian pada anak sekolah usia 13-14 tahun dengan menggunakan kuesioner ISAAC (International Study on Asthma and Allergy in Children) tahun 1995 melaporkan prevalensi asma sebesar $2,1 \%$, sedangkan pada tahun 2003 meningkat menjadi 5,2\%. Hasil survei asma pada anak sekolah di beberapa kota di Indonesia (Medan, Palembang, Jakarta, Bandung, Semarang, Yogyakarta, Malang dan Denpasar) menunjukkan prevalensi asma pada anak SD (6 sampai 12 tahun) berkisar antara 3,7-6,4\%, sedangkan pada anak SMP di Jakarta Pusat sebesar 5,8\%. Jika demikian, penyakit asma perlu mendapat perhatian serius sebab telah menjadi masalah kesehatan masyarakat. ${ }^{3}$

Tes fungsi paru (TFP) dapat berperan baik dalam diagnosis penyakit paru-paru. Hal ini juga berguna dalam menilai pertumbuhan dan kematangan fungsi paru-paru yang berjalan berdampingan dengan pertumbuhan somatik. Sehubungan dengan itu, terdapat peningkatan linear dari fungsi paru-paru oleh kemajuan pertumbuhan sel-sel tubuh. ${ }^{4}$ Diperlukan tes fungsi paru (TFP) pada penyakit asma yang bermanfaat dalam diagnosis dan pengobatan asma. Nilai prediksi tes fungsi paru dapat berdasarkan beberapa variabel seperti umur, tinggi badan, berat badan, rentang tangan, luas area tubuh dan jenis kelamin. Selain itu, untuk diagnosis dan evaluasi pada parameter TFP dibutuhkan sebuah persamaan prediksi yang spesifik pada populasi dengan juga memperhitungkan suku, ras, sosial, dan faktor ekonomi. ${ }^{5}$

Rentang tangan merupakan salah satu pengukuran fisik yang menggunakan panjang dari satu ujung tangan individu (diukur pada ujung jari) ke ujung yang lain ketika diangkat sejajar dengan tanah setinggi bahu pada sudut seratus delapan puluh derajat. Tinggi badan suatu individu berkorelasi kuat dengan rentang tangan. ${ }^{6}$ Usia dan jenis kelamin harus diperhitungkan untuk mendapatkan prediksi terbaik dari menghitung tinggi badan menggunakan rentang tangan. ${ }^{7}$ Tinggi badan juga digunakan untuk menentukan standar dan prediksi volume paru. ${ }^{8}$ Penggunaan tinggi badan dapat digantikan dengan rentang tangan apabila tinggi badan saat berdiri telah dipengaruhi oleh berbagai penyakit, sebagai contoh pada kifosis dan kifoskoliosis. Pada penderita asma terkadang didapatkan deformitas dada ditandai dengan penonjolan tulang dada dan tulang rusuk yang disebut pectus carinatum atau pigeon chest. Di samping itu, anak dengan pigeon chest sering diikuti dengan scoliosis dan artritis..$^{9}$ Selain itu, pada penderita asma dapat menggunakan penilaian fungsi paru dari pengukuran rentang tangan untuk menghindari komplikasi dari pemeriksaan fungsi paru seperti keadaan pingsan dan sebagainya.

Berbagai penelitian di negara-negara lain telah menunjukkan bahwa perbedaan variabel bebas seperti rentang tangan, tinggi badan, tinggi lutut, panjang ulna, dan demi span mempengaruhi nilai fungsi paru-paru pada anak-anak sekolah. Sejumlah besar studi ${ }^{8,10}$ telah menunjukkan bahwa nilai normal TFP pada anak-anak India berbeda dengan di negara-negara Barat dan lainnya serta ada variasi regional dalam nilai-nilai TFP..$^{11}$ Oleh karena itu, hasil dari penelitian sebelumnya di negara lain belum tentu dapat diterapkan di Indonesia. Beberapa penelitian mengenai hubungan rentang tangan dengan fungsi paru pada dewasa sudah banyak namun pada anak masih jarang. Di Indonesia, penelitian mengenai hubungan antara rentang tangan dan fungsi paru pada anak yang menderita penyakit asma belum pernah dilakukan Melalui penelitian ini, diharapkan akan mengetahui persamaan (equation) nilai prediksi fungsi paru dari pengukuran rentang tangan dengan uji regresi linier sederhana.

\section{METODE}

Penelitian ini merupakan penelitian observasional analitik dengan desain penelitian cross sectional. Penelitian dilakukan pada bulan Maret-Juni 2015 di SDN Karangrejo 01, SDN Bendungan, dan SDN Lempongsari, Kecamatan Gajah Mungkur, Semarang. Sampel penelitian diporelah secara stratified random sampling yaitu 16 kecamatan di Semarang diacak untuk diambil 1 kecamatan, kemudian sekolah dasar dalam 1 kecamatan akan diacak untuk diambil 3 sekolah dasar.Subjek yang diambil dari 3 sekolah dasar tersebut akan dipilih berdasarkan kriteria inklusi yaitu anak 6 - 12 tahun dan setuju untuk ikut penelitian, sedangkan anak dengan disabilitas atau deformitas ekstremitas dan tulang belakang serta memiliki penyakit genetik seperti Marfan's syndrome tidak diikutsertakan. Total subyek penelitian ini adalah 350 responden. Analisis statistik dilakukan dengan menggunakan program IBM SPSS 22.0 for Windows. 


\section{HASIL DAN PEMBAHASAN}

Didapatkan subjek sebanyak 350 responden pada rentang periode penelitian Maret - Juni 2015, namun hanya 349 kuesioner ISAAC yang kembali. Kuesioner ISAAC menunjukkan prevalensi asma sebesar 10,9\% dan insidensi sebesar 9,2\%. Hasil tersebut menunjukkan terdapat 38 anak yang mempunyai riwayat asma. Hampir semua anak yang mengembalikan kuesioner ISAAC juga diukur indeks antropometri dan tes fungsi paru yaitu sebanyak 341 anak. Hanya 30 responden yang memenuhi kriteria penelitian yaitu memiliki riwayat asma yang dievaluasi melalui kuesioner ISAAC dan telah melakukan pengukuran antropometri dan tes fungsi paru secara lengkap walaupun hasil spirometri menunjukkan nilai yang normal. Jumlah responden laklaki dan perempuan hampir setara, subjek terdiri dari 13 anak laki-laki dan 17 anak perempuan dengan rentang usia minimal 6 tahun dan maksimal 12 tahun, serta rerata usia $9,4 \pm 1,52$ tahun.
Data antropometri yang diukur dalam penelitian ini meliputi: tinggi badan, berat badan, dan rentang tangan; yang disajikan dalam tabel 2.

Nilai tes fungsi paru yang diukur menggunakan Spirometer dalam penelitian ini meliputi FVC, FEV1, FEV1/FVC, dan PEFR; yang disajikan dalam tabel 3.

Untuk mengetahui hubungan rentang tangan dan nilai tes fungsi paru, maka dilakukan perhitungan menggunakan uji Spearman karena didapatkan distribusi tidak normal pada tes normalitas, yang disajikan dalam tabel 4 .

Berdasarkan tabel 4 didapatkan nilai kekuatan hubungan $(r)$ sangat lemah yaitu pada rentang dengan FEV1/FVC dan FEV1 dengan FEV1/FVC. Nilai kekuatan hubungan $(r)$ lemah didapatkan pada FEV1/FVC dengan PEF. Rentang tangan dengan FVC, rentang tangan dengan FEV1, FVC dengan FEV1, dan FVC dengan PEF menunjukkan nilai kekuatan hubungan $(r)$ sedang. Nilai kekuatan hubungan $(r)$ kuat didapatkan pada rentang tangan dengan PEF dan FEV1 dengan PEF. Nilai

TABEL 1

Distribusi jenis kelamin subjek penelitian

\begin{tabular}{lcc} 
Jenis Kelamin & Jumlah & Persentase (\%) \\
\hline Laki-Laki & 13 & 43,33 \\
Perempuan & 17 & 57,67 \\
Total & 30 & 100 \\
\hline
\end{tabular}

TABEL 2

Distribusi jenis kelamin subjek penelitian

\begin{tabular}{lccccc}
$\begin{array}{l}\text { Parameter antropometri } \\
(\boldsymbol{n}=\mathbf{3 4 1})\end{array}$ & Minimal & Maksimal & Median & Rerata & $\begin{array}{c}\text { Simpang } \\
\text { Baku }\end{array}$ \\
\hline Tinggi badan $(\mathrm{cm})$ & 108,7 & 158,8 & 132,6 & 131,83 & 10,50 \\
Berat badan $(\mathrm{kg})$ & 15,8 & 77,4 & 28,8 & 31,12 & 10,53 \\
Rentang tangan $(\mathrm{cm})$ & 105,7 & 160,2 & 132,7 & 131,99 & 11,58 \\
\hline
\end{tabular}

TABEL 3

Hasil pengukuran spirometri subjek penelitian

\begin{tabular}{lccccc|}
$\begin{array}{l}\text { Parameter tes fungsi paru } \\
(\boldsymbol{n}=\mathbf{3 0})\end{array}$ & Minimal & Maksimal & Median & Rerata & $\begin{array}{c}\text { Simpang } \\
\text { Baku }\end{array}$ \\
\hline FVC (L) & 1,15 & 2,89 & 1,495 & 1,741 & 0,4922 \\
FEV1 (L) & 1,01 & 2,49 & 1,37 & 1,543 & 0,399 \\
FEV1/FVC (\%) & $62,34 \%$ & $98,57 \%$ & $90,57 \%$ & $89,69 \%$ & $8,98 \%$ \\
PEFR (L/s) & 1,64 & 4,83 & 2,975 & 3,147 & 0,756 \\
\hline
\end{tabular}




\begin{tabular}{|c|c|c|c|c|c|c|c|}
\hline \multicolumn{8}{|c|}{ Korelasi rentang tangan dan nilai fungsi paru } \\
\hline & & & $\begin{array}{c}\text { Rentang } \\
\text { tangan }\end{array}$ & FVC & FEV1 & $\begin{array}{l}\text { FEV1/ } \\
\text { FVC }\end{array}$ & PEFR \\
\hline \multirow[t]{10}{*}{ Spearman's rho } & $\begin{array}{l}\text { Rentang } \\
\text { tangan }\end{array}$ & $\begin{array}{l}\text { Koefisien } \\
\text { korelasi }\end{array}$ & 1.000 & 0,529 & 0,580 & $-0,063$ & 0,607 \\
\hline & & $p$ & - & $0,003 *$ & $0,001 *$ & 0,742 & $0,000 *$ \\
\hline & FVC & $\begin{array}{l}\text { Koefisien } \\
\text { korelasi }\end{array}$ & 0,529 & 1.000 & 0,869 & $-0,063$ & 0,467 \\
\hline & & $p$ & $0,003^{*}$ & - & $0,000 *$ & $0,020^{*}$ & $0,009 *$ \\
\hline & FEV1 & $\begin{array}{l}\text { Koefisien } \\
\text { korelasi }\end{array}$ & 0,580 & 0,869 & 1.000 & $-0,017$ & 0,618 \\
\hline & & $p$ & $0,001^{*}$ & $0,000 *$ & - & 0,927 & $0,000^{*}$ \\
\hline & FEV1/FVC & $\begin{array}{l}\text { Koefisien } \\
\text { korelasi }\end{array}$ & $-0,063$ & $-0,424$ & $-0,017$ & 1.000 & 0,225 \\
\hline & & $p$ & 0,742 & $0,020^{*}$ & 0,927 & - & 0,232 \\
\hline & PEFR & $\begin{array}{l}\text { Koefisien } \\
\text { korelasi }\end{array}$ & 0,607 & 0,467 & 0,618 & 0,225 & 1.000 \\
\hline & & $p$ & $0,000 *$ & $0,009 *$ & $0,000^{*}$ & 0,232 & - \\
\hline
\end{tabular}

*Signifikan $p<0,05$

kekuatan hubungan $(r)$ sangat kuat didapatkan pada FVC dengan FEV1. Untuk nilai korelasi dengan nilai positif $(+)$ misalnya pada rentang tangan dengan FVC, FEV1, dan PEF. Nilai tersebut menunjukkan bahwa arah korelasi searah yang berarti semakin besar satu variabel maka semakin besar variabel lainnya begitu juga sebaliknya.

Berdasarkan hasil uji Spearman's rho secara keseluruhan menunjukkan nilai $p$ yang signifikan sehingga dapat diamati sebuah korelasi positif yang signifikan antara FVC, FEV1, PEFR dan indeks antropometri. Rentang tangan ditemukan memiliki pengaruh sedang sampai kuat pada parameter paru. Sebuah korelasi negatif dan tidak signifikan terdapat pada rentang tangan dan FEV1.

Persamaan nilai prediksi fungsi paru dapat diketahui dengan data antropometri dan nilai tes fungsi paru yang meliputi FVC, FEV1, FEV1/FVC, dan PEF menggunakan uji regresi linier; yang disajikan dalam tabel 5 .

Persamaan regresi yang telah didapatkan dari hasil penelitian ini dapat menunjukkan bahwa tinggi badan dan berat badan sangat mempengaruhi nilai FVC.Selain itu, dapat diamati juga bahwa tinggi badan dan rentang tangan sangat mempengatuhi nilai FEV1. Indeks antropometri yang sangat mempengaruhi PEFR adalah usia, tinggi badan, dan rentang tangan. Apabila diamati, tinggi badan memberi pengaruh paling besar pada nilai PEFR diikuti oleh rentang tangan.

\section{SIMPULAN}

Berdasarkan hasil analisis, variabel seperti FVC, FEV1, dan PEFR menunjukkan korelasi positif yang signifikan dengan rentang tangan pada anak asma. Hubungan yang paling kuat terdapat pada parameter fungsi paru PEFR dengan rentang tangan. Didapatkan rerata rentang tangan pada anak asma usia sekolah yaitu 134,3 $\pm 9,84 \mathrm{~cm}$. Selain itu, didapatkan nilai rerata masing-masing parameter fungsi paru yaitu FVC $(1,74 \pm 0,49)$ L, FEV1 $(1,54 \pm 0,39)$ L, FEV1\% $(89,7 \% \pm 8,98 \%)$, dan PEFR $(3,15 \pm 0,75) \mathrm{L} / \mathrm{s}$. Serta telah didapatkan juga persamaan nilai prediksi fungsi paru dari rentang tangan antara lain $\mathrm{FVC}=0,025 * \mathrm{RT}-1,676 \mathrm{FEV} 1=0,23 * \mathrm{RT}-1,482$, dan $\mathrm{PEFR}=0,043 * \mathrm{RT}-2,592$.

Persamaan tersebut tidak akurat untuk diaplikasikan dan digeneralisasikan untuk seluruh anakanak di Indonesia dengan riwayat asma dikarenakan jumlah sampel anak asma yang terlalu sedikit.Perlu penelitian lebih lanjut untuk kepentingan klinis mengenai pengukuran rentang tangan yang dapat digunakan untuk memprediksi nilai fungsi paru khususnya pada anak asma. Selain itu, belum adanya persamaan prediksi berdasarkan protokol standarisasi 


\section{TABEL 5}

\section{Persamaan regresi untuk fungsi paru dan parameter antropometrik}

\begin{tabular}{|c|c|c|c|c|c|}
\hline $\begin{array}{l}\text { Variabel } \\
\text { terikat }\end{array}$ & Persamaan regresi & $\mathbf{R}$ & $\mathbf{R}^{2}$ & $\boldsymbol{p}$ & SEE \\
\hline \multirow[t]{5}{*}{ FVC } & $\mathrm{FVC}=0,093 *$ Age $+0,872$ & 0,286 & 0,082 & 0,126 & 0,488 \\
\hline & $\mathrm{FVC}=-0,282 * \mathrm{Sex}+2,184$ & 0,284 & 0,081 & 0,128 & 0,488 \\
\hline & $\mathrm{FVC}=0,036 *$ Height $-3,067$ & 0,580 & 0,336 & $0,001 * *$ & 0,415 \\
\hline & $\mathrm{FVC}=0,023 *$ Weight $+0,983$ & 0,563 & 0,317 & $0,001 * *$ & 0,421 \\
\hline & $\mathrm{FVC}=0,025^{*}$ ArmSpan $-1,676$ & 0,509 & 0,259 & 0,232 & 0,438 \\
\hline \multirow[t]{5}{*}{ FEV1 } & FEV1 $=0,084 *$ Age $+0,753$ & 0,32 & 0,103 & 0,084 & 0,391 \\
\hline & FEV $1=-0,247 * \operatorname{Sex}+1,93$ & 0,307 & 0,094 & 0,099 & 0,393 \\
\hline & FEV1 $=0,032 *$ Height $-2,67$ & 0,627 & 0,393 & $0,000 * *$ & 0,321 \\
\hline & FEV1 $=0,015 *$ Weight $+1,05$ & 0,452 & 0,204 & 0,012 & 0,368 \\
\hline & $\mathrm{FEV} 1=0,23^{*}$ ArmSpan $-1,482$ & 0,555 & 0,308 & $0,001 * *$ & 0,343 \\
\hline \multirow[t]{5}{*}{ FEV1\% } & FEV1\%=-0,000077*Age $+0,898$ & 0,001 & 0,000 & 0,995 & 0,093 \\
\hline & FEV $1 \%=-0,004 *$ Sex $+0,903$ & 0,021 & 0,000 & 0,914 & 0,092 \\
\hline & FEV1\%=0*Height $+0,952$ & 0,036 & 0,001 & 0,849 & 0,092 \\
\hline & FEV1\%=-0,002*Weight $+0,972$ & 0,307 & 0,094 & 0,098 & 0,088 \\
\hline & FEV1\%=0*ArmSpan+0,915 & 0,015 & 0,000 & 0,937 & 0,092 \\
\hline \multirow[t]{5}{*}{ PEFR } & PEFR $=0,244 *$ Age $+0,865$ & 0,488 & 0,238 & $0,006 * *$ & 0,683 \\
\hline & PEFR $=-0,356 *$ Sex $+3,704$ & 0,233 & 0,54 & 0,216 & 0,761 \\
\hline & PEFR $=0,06 *$ Height $-4,875$ & 0,63 & 0,396 & $0,000 * *$ & 0,608 \\
\hline & PEFR $=0,022 *$ Weight $+2,434$ & 0,344 & 0,119 & 0,062 & 0,735 \\
\hline & PEFR $=0,043 *$ ArmSpan-2,592 & 0,556 & 0,309 & $0,001 * *$ & 0,65 \\
\hline
\end{tabular}

** Signifikan $p<0,01$

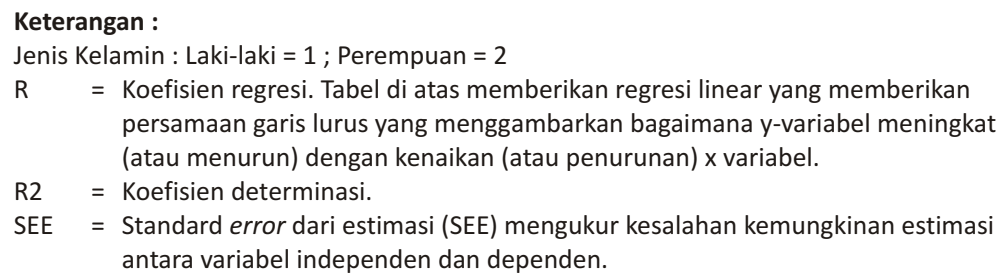

spirometri terkini pada anak normal dan anak asma di Indonesia sangat penting untuk dibuat dengan lebih banyak diteliti. Bagi penelitian selanjutnya, untuk meningkatkan keakuratan rumus prediksi nilai fungsi paru dari berbagai indeks antropometri seperti rentang tangan.

\section{DAFTAR PUSTAKA}

1. Faisal Y.30 Gangguan Kesehatan pada Anak Usia Sekolah.Jakarta: Yayasan Obor Indonesia.2005:53-54.

2. Mason Robert J, Murray John F, Broaddus VC, Nadel Jay A, Martin Thomas R, Talmadge E. et.al.Murray and Nadel's 
textbook of respiratory medicine,5th ed. "CHAPTER 38 Asthma." Elsevier.2010:1171.

3. Baratawidjaja KG, Soebaryo RW, Kartasasmita CB, Suprihati, Sundaru H, Siregar SP, et al. Allergy and asthma, The scenario in Indonesia. In: Shaikh WA.editor. Principles and practice of tropical allergy and asthma. Mumbai: Vicas Medical Publishers.2006:707-36.

4. Deshpande JN, Dahat HB, Shirole CD, Pandc AH. Pulmonary function and their correlation with anthropometric parameters in rural children. Indian J Pediatr. 1983;50:375-8.

5. Connett GJ, Quak SH, Wong ML, Teo J, Lee BW. Lung function reference values in Singaporean children aged 6-18 years. Thorax. 1994;49:901-5.

6. Yabanci N, Kiliç S, Simşek I. The relationship between height and arm span, mid upper arm and waist circumferences in children.Annals of Human Biology. 2010;37(1):70-5.

7. Tan MP, Wynn NN, Umerov M, Henderson A, Gillham A, Junejo S et al. Arm Span to Height Ratio Is Related to Severity of Dyspnea, Reduced Spirometry Volumes, and Right Heart Strain. Chest. 2009;135 (2):448454.
8. Zverev Y, Chisi J. Estimating Height from Arm Span Measurement in Malawian Children. Coll Antropol. 29(2005) 2:469-73.

9. Cincinnati Childrens.Pectus Carinatum[Online].2013 November [ Cited 2015 February] Available from:URL: http://www.cincinnatichildrens.org/health/p/pectuscarinatum/

10. Raju PS, Prasad KV, Ramana YV, et al. Study on lung function tests and Prediction equations in Indian male children. Indian Pediatr. 2003;40(8):705 $\square 11$.

11. Pellegrino R, Viegi G, Brusasco V, Crapo RO, Burgos F, Casaburi $\mathrm{R}$ et al.Interpretative strategies for lung tests.Eur Respir J.2005.26:94868. 